\title{
Antifungal Resistance Analysis of Environmental Isolates of Aspergillus in North India
}

\author{
Shanu Hoda, Harshita Agarwal, Simran K. Ahluwalia, Maansi Vermaniand Pooja \\ Vijayaraghavan*
}

Antimycotic and Drug Susceptibility Laboratory, J-3 Block, Amity Institute of Biotechnology, Sector-125, Amity University, Uttar Pradesh, Noida, India.

\begin{abstract}
Triazoles are the major group of antifungals for treating Aspergillus infections. The morbidity and mortality associated with these infections is high and rate of treatment failure is more in patients infected with azole resistant Aspergillus. The azole resistant Aspergillus isolates have been recovered from both azole treated and azole naive patients. Thus, there may be an environmental route of exposure to azole resistant Aspergillus. The present study was envisaged for the isolation and enumeration of environmental isolates of Aspergillus resistant to medically available antifungal azole drugs in North Indian environment. A total of $\mathbf{2 5}$ soil samples were collected from North Indian agricultural farms where azole pesticides were being used. The soil samples were screened for Aspergillus isolates by serial dilution pour plate method. Further, their drug susceptibility testing was performed using disc diffusion, E- strip and micro-broth dilution method against medically available triazoles: itraconazole, ketoconazole, fluconazole and voriconazole. A total of 41 Aspergillus species were isolated from the soil samples. Based on conventional microscopic assay, 13 of them were identified as Aspergillus fumigatus, 9 as Aspergillus niger, 5 as Aspergillus terreus, 3 as Aspergillus nidulans, 1 as Aspergillus flavus and 9 as other Aspergillus species. Resistance for all tested antifungal drugs was detected in $7.3 \%$ Aspergillus isolates and $\mathbf{4 3 . 7 \%}$ isolates were resistant to any of the tested azole drugs. The results demonstrated that Aspergillus isolates resistant to medical triazoles are present in the agricultural farms.
\end{abstract}

Keywords: Aspergillus, Antifungals, Azole resistance, Antifungal susceptibility test.

\footnotetext{
*Correspondence: vrpooja@amity.edu; +91-9650548930
}

(Received: 15 January 2019; accepted: 02 March 2019)

Citation: Shanu Hoda, Harshita Agarwal, Simran K. Ahluwalia, Maansi Vermani and Pooja Vijayaraghavan, Antifungal Resistance Analysis of Environmental Isolates of Aspergillus in North India, J Pure Appl Microbiol., 2019; 13(1):385-392 doi: 10.22207/ JPAM.13.1.42

(C) The Author(s) 2019. Open Access. This article is distributed under the terms of the Creative Commons Attribution 4.0 International License which permits unrestricted use, sharing, distribution, and reproduction in any medium, provided you give appropriate credit to the original author(s) and the source, provide a link to the Creative Commons license, and indicate if changes were made. 


\section{INTRODUCTION}

Azoles are the common synthetic compounds that inhibit sterol biosynthesis. They are used as first choice of treatment against Aspergillus infections in humans. Besides, they are also used for preservation and plant protection (Horsfall, 1975; Hof, 2001; Russel, 2005; e Ribas et al., 2016). These have been widely used to treat human mycoses and plant pathogens effectively since 1970s and have similar mode of action in humans and plant fungal infections (Snelders et al., 2009; Cools et al., 2013). It has been reported that among 38 registered fungicides in India (Central Insecticide Board, Govt. of India), 14 are azole pesticides. Majority of these broad range azole fungicides used by farmers have negative impact on environment and human health (Berger et al., 2017). Large scale use of azole fungicide in agriculture is causing mutational resistance in Aspergillus species which are present in abundance in environment (Kumar et al., 2013). There have been various reports stating the emergence of cross- and multi- drug resistance of human pathogen Apergillus is related to the exposure of fungicides in the agro-ecosystem (Meneau and Sanglard, 2005; Bowyer and Denning, 2013; Lelievre et al., 2013). Azole pesticides have been used in agriculture during pre and post harvesting of crops to avoid the spoilage (Snelders et al., 2012). These pesticides persist in the soil for longer time, accumulate in plants and are transferred to humans through food web (Palazzini et al., 2018). These conditions enhance the development of azole resistant strains.

Azole drug resistance in patients suffering from Aspergillus infections has emerged as a global issue in recent years due to failure of drug efficacy, thereby increasing the mortality and morbidity rate. In India, $64 \%-71 \%$ of multi-triazole resistant strains have been isolated from in patients suffering from Aspergillus infections who were never been exposed to triazole treatments (Chang et al., 2016). Hence, an environmental origin for triazole resistant Aspergillus strains has been proposed. The probable reasons for the emergence of azole resistant strains in the environment include changes in drug target affinity (Perlin et al., 2015) and excessive use of azole pesticides in the agriculture (Verweij et al., 2009; Chowdhary et al., 2012). The Fungicide Resistance Action Committee (FRAC) fixes the baseline resistance level of fungi prior to commercialization of a fungicide whereas, the failures in disease control and detection of resistant isolates even below the baseline are the clear mark of the hazards of fungicide resistance development (Brent and Hollomon, 2007). The spores of the azole-pesticide resistant environmental strain of Aspergillus when inhaled by immuno-compromised individuals cause antifungal azole-resistant diseases, leading to treatment failure and deaths in patients (Pham et al., 2014).

The proposition of emergence of azole-resistant Aspergillus species due to azole fungicides in agri-ecosystem was initially suggested by studies conducted in the Netherland, where the triazole resistant Aspergillus was reported for the first time (Snelders et al., 2008). Later corroborated studies were conducted in Spain, Belgium, Norway, Great Britain, Denmark France, China, Italy, Austria and India (Rodriguez-Tudela et al., 2008; Howard et al., 2010; Mortensen et al., 2010; Lockhart et al., 2011; Burgel et al., 2012; Van der Linden et al., 2015). The varying rates of azole resistant Aspergillus has been documented across the world ranging from $0.6 \%$ to $38 \%$ (Snelders et al., 2008; Howard et al., 2009; Bueid et al., 2010; Mortensen et al., 2010; van der Linden et al., 2011; Burgel et al., 2012; Chowdhary et al., 2012; Badali et al., 2013; Bader et al., 2013; Pham et al., 2014; van Ingen et al., 2015). In India, 7\% environmental isolates and $1.75 \%$ Clinical isolates of Aspergillus strains have been reported to be multi-triazole resistant (Chowdhary et al., 2012; Chowdhary et al., 2015). All these epidemiological studies revealed that there is the link between triazole resistant clinical isolates and the widespread use of azole fungicides. Thus, continued surveillance of resistance in environmental Aspergillus strains is crucial. The present study was envisaged to study the prevalence of azole resistant Aspergillus species in agricultural fields of north western India.

\section{MATERIALS AND METHODS}

\section{Soil sample collection}

A total of 25 soil samples from various regions of North Indian farms were collected (Fig 1): Amritsar $(n=2)$, Chandigarh $(n=3)$, Hisar ( 
$=2)$, Rohtak $(n=2)$, Ghevra $(n=2)$, Bawana $(n=$ $4)$, Noida $(n=2)$, Greater Noida $(n=2)$, Gonda ( $n$
$=2)$, Varanasi $(n=2)$ and Singrauli $(n=2)$. The soil samples were coded as NIS-001 to NIS-025.

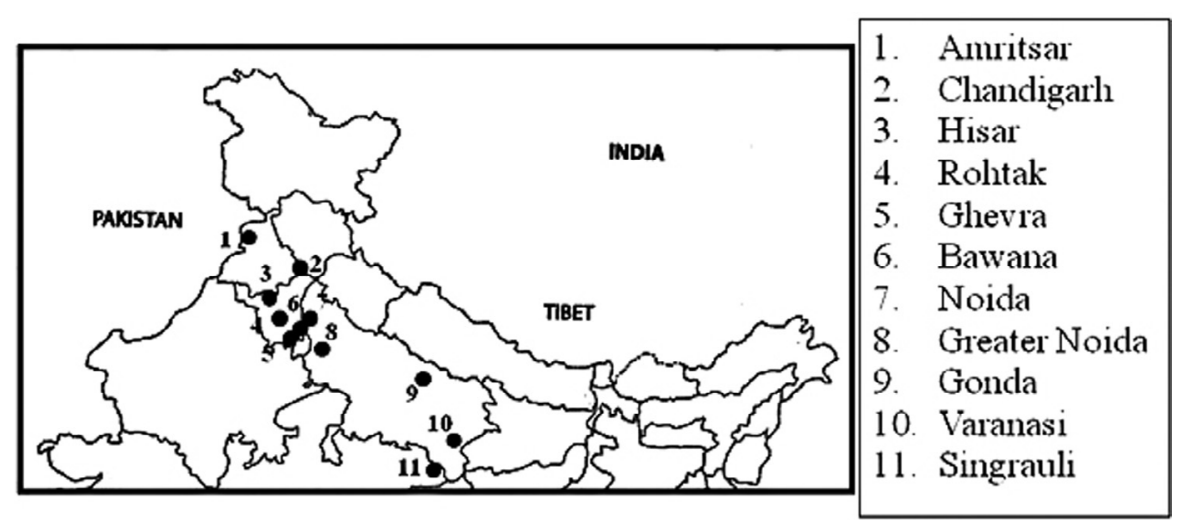

Fig. 1. Sites of sample collection in North India

Screening and isolation of environmental $\boldsymbol{A}$. fumigatus from soil samples

Soil samples were processed for isolation of Aspergillus colonies using serial dilution method (Chowdhary et al., 2012). Briefly, $1 \mathrm{~g}$ of soil was dissolved in $10 \mathrm{ml}$ of $0.9 \%$ normal saline, vortexed and allowed to settle for 30 seconds. From this stock suspension, $10^{-1}-10^{-4}$ dilutions were prepared and $50 \mu \mathrm{l}$ of each dilution were spread on potato dextrose agar (PDA) plates supplemented with $0.5 \mathrm{mg} / \mathrm{ml}$ chloramphenicol. The plates were incubated for 5 days at $28^{\circ} \mathrm{C}$. Each experiment was conducted in triplicates.

The macroscopic features like colony colour, texture were studied. The fungal colonies were identified by conventional microscopy and then by following mycological literature (de Hoog et al., 2000; Klich, 2002; McClenny, 2005). The filamentous colonies on PDA plates were teased apart and stained with lacto-phenol cotton blue and conidial heads, vesicle shape, seriation and conidia shape were investigated under light microscope at 40X magnification for identification of Aspergillus species (Nugent et al., 2006).

Procurement of azole-susceptible A. fumigatus, antifungal azole discs and e-strips

A. fumigatus (NAIMCC-F-02473) was procured from National Bureau of Agriculturally Important Microorganisms (NBAIM), Mau, India. The fungal strain was maintained by sub-culturing on PDA slants at $28 \pm 2^{\circ} \mathrm{C}$ for 5 days to obtain conidial growth. The organism was maintained at $4^{\circ} \mathrm{C}$ and sub cultured every 15 days.

Antifungal discs and e-strips of itraconazole, ketoconazole, fluconazole and voriconazole were procured from Himedia Chemicals.

\section{Disc diffusion assay}

Aspergillus conidia were harvested in sterile $0.85 \%$ saline, conidial suspension was adjusted to $10^{6}$ conidia per $\mathrm{ml}$ and $50 \mu \mathrm{l}$ of this suspension was inoculated on PDA plate. Discs containing the itraconazole $(10 \mu \mathrm{g} / \mathrm{disc})$, ketoconazole $(10 \mu \mathrm{g} / \mathrm{disc})$, fluconazole $(10 \mu \mathrm{g} /$ disc) and voriconazole $(1 \mu \mathrm{g} / \mathrm{disc})$ were impregnated to the surfaces of inoculated plates. Plates were incubated at $28^{\circ} \mathrm{C}$ for 5 days to allow fungal growth. Zone of inhibition diameters were measured in millimetres (Nweze et al., 2010). An azole-susceptible $A$. fumigatus (NAIMCC-F-02473) was used as control. All the experiments were run in triplicates.

\section{E-strip test}

Susceptibility to different azoles in Aspergillus isolates was determined by E-strip test as described by Pfaller et al., 2003 with minor modifications. Isolates of Aspergillus species were allowed to sporulate on PDA slants for 5 days. Conidial suspensions were prepared in $0.9 \%$ normal saline supplemented with $0.1 \%$ Tween-20. The concentration was adjusted to an optical density of $0.09-0.13$ at $530 \mathrm{~nm}$. The PDA culture plates were inoculated with $50 \mu$ l of prepared conidial suspension. The E-strip of itraconazole 
$(0.002-32 \mu \mathrm{g} / \mathrm{ml})$, ketoconazole $(0.002-32 \mu \mathrm{g} / \mathrm{ml})$, fluconazole $(0.016-256 \mu \mathrm{g} / \mathrm{ml})$ and voriconazole $(0.002-32 \mu \mathrm{g} / \mathrm{ml})$ was placed across the central surface of the freshly inoculated PDA plate. An azole-susceptible control strain $A$. fumigatus (NAIMCC-F-02473) was used. The plates were incubated at $28^{\circ} \mathrm{C}$ and results were recorded for 5 days post inoculation.

\section{Antifungal susceptibility testing (AFST)}

Aspergillus isolates resistant to all tested azole drugs on agar plates were subjected to AFST using CLSI M38-A2 broth micro-dilution method (Clinical and Laboratory Standards Institute, 2008) for filamentous fungi. Briefly, $0.4 \times 10^{4}$ to $5 \times 10^{4}$ Aspergillus conidia/ml were added to 96-well micro-titre flat-bottom plate (Tarson) consisting of media with azole drugs ranging from $500 \mu \mathrm{g} / \mathrm{ml}$ to $0.97 \mu \mathrm{g} / \mathrm{ml}$. Minimum inhibitory concentration $\left(\mathrm{MIC}_{100}\right.$ ) was read after $48 \mathrm{~h}$ as the concentration of drug at which no visible fungal growth was observed. The AFST results were analyzed by using epidemiological cut-off values (ECVs) proposed by Espinel-Ingroff et al., 2011a. For itraconazole, voriconazole and ketoconazole $\mathrm{MIC}_{100}>1 \mu \mathrm{g} / \mathrm{ml}$ were considered as ECVs for resistant isolates. However, fluconazole $\mathrm{MIC}_{100}>64 \mu \mathrm{g} / \mathrm{ml}$ were ECVs for resistant isolates of $A$. fumigatus, Aspergillus flavus and Aspergillus nidulans. MIC100> 4 $\mathrm{g} /$ $\mathrm{ml}$ was ECV for Aspergillus terreus. Clinical breakpoints $>2 \mu \mathrm{g} / \mathrm{ml}$ have been considered for resistant $A$. fumigatus (Lass-Florl, 2014; AlastrueyIzquierdo et al., 2015).

\section{RESULTS AND DISCUSSION}

The emergence of drug-resistant strains has become a challenge for treating Aspergillus diseases especially among immune-compromised patients. The majority of cases of azole-resistant diseases are due to resistant Aspergillus originating from the environment (Verweij et al., 2016). In the present epidemiological study, we have studied the presence of azole resistant Aspergillus species in agricultural fields of North India. A total of 165 fungal isolates having different morphological characteristics were recovered from 25 soil samples collected from different sites. Conidial head and shape is important feature for fungal identification (Khalil and Hashem 2018). On the basis of microscopic and morphological examination, $24.8 \%$ were Aspergillus isolates.
Further, out of these isolates, $31.7 \%(n=13)$ were A. fumigatus, $21.9 \%(\mathrm{n}=9)$ were Aspergillus niger, $12.1 \%(n=5)$ were $A$. terreus, $7.3 \%(n=3)$ were $A$. nidulans, $2.4 \%(n=1)$ were $A$. flavus and $21.9 \%$ $(n=9)$ were identified as other Aspergillus species microscopically. All these isolates were screened for their azole resistance using Disc diffusion assay, E-strip test and broth micro-dilution method. In an investigation during 2012-13, 27 soil samples from Delhi and 10 soil samples from Varanasi yielded 88 and $38 \mathrm{~A}$. fumigatus strains respectively, which were later screened for their triazole resistance (Chowdhary et al., 2014).

\section{Disc diffusion method}

Disc tests are inexpensive and easy to set up, and provide an ideal screening test (Alastruey-Izquierdo et al., 2015). Clinically used triazole antifungals are derivatives of either fluconazole (voriconazole and isavuconazole) or ketoconazole (itraconazole and posaconazole) as the lead compound (Dudakova et al., 2017). Therefore, in the present study voriconazole, itraconazole, ketoconazole and fluconazole were used as screening drugs. Among 13 isolates of $A$. fumigatus, 3 isolates had no inhibition zone against any azole antifungal drugs i.e. resistant to triazoles. The other isolates were resistant to atleast one azole drugs. The inhibition zones of Aspergillus isolates are presented in Table 1. The inhibition zone ranges reported for $A$. fumigatus susceptible strains against itraconazole and voriconazole were 11 to $21 \mathrm{~mm}$ and 25 to $33 \mathrm{~mm}$, respectively (Espinel-Ingroff et al., 2011b, Al-Wathiqi et al., 2013). Similar results were observed in the present study.

\section{E-strip test}

Agar based E-strip test is the modification of the CLSI reference method and is convenient and flexible (Posteraro and Sanguinetti, 2014). The strains AF-003, AF-006 and AF-008 were selected for E-strip test on the basis of disc diffusion assay, showing no inhibition zone for any of the tested azoles (Fig 2). E-strip test results were also consistent with the results of disc diffusion assay, where the drugs strips had no/negligible inhibitory effect on resistant isolates. According to Alastruey-Izquierdo et al., 2015, the E-strip test of itraconazole reveals a good correlation with the CLSI M38-AFST to detect Aspergillus resistance than other antifungal drugs. 
Table 1. Zone of inhibition (in $\mathrm{mm}$ ) of all Aspergillus isolates against tested azole antifungals

\begin{tabular}{|c|c|c|c|c|}
\hline Isolates & Itraconazole & Ketaconazole & Fluconazole & Voriconazole \\
\hline \multicolumn{5}{|c|}{$\begin{array}{l}\text { Reference } \\
\text { strain }\end{array}$} \\
\hline $\mathrm{AF}^{\#}$ & 19.1 & 25.1 & 8.2 & 26 \\
\hline \multicolumn{5}{|c|}{ A. fumigatus } \\
\hline AF-001 & 10 & 18.2 & - & - \\
\hline AF-002 & 13 & - & - & 18 \\
\hline AF- $003^{*}$ & - & - & - & - \\
\hline AF-004 & 21.2 & - & - & 14.5 \\
\hline AF-005 & 12.3 & 19.8 & 4.4 & 6.8 \\
\hline$A F-006^{*}$ & - & - & - & - \\
\hline AF-007 & 15.2 & 17.4 & - & 10 \\
\hline AF-008* & - & - & - & - \\
\hline AF-009 & 13.6 & 18 & - & - \\
\hline AF-010 & 9.2 & - & - & 4.2 \\
\hline AF-011 & 8.4 & 17.2 & - & 2.2 \\
\hline AF-012 & 11.4 & - & - & - \\
\hline AF-012 & 21 & 19.3 & - & - \\
\hline AF-013 & 10.8 & 14.2 & 1.5 & 3.4 \\
\hline \multicolumn{5}{|c|}{ A. nidulans } \\
\hline ANd-001 & 50 & 40 & 12 & 22.4 \\
\hline ANd-002 & 35 & 36.4 & - & 40 \\
\hline ANd-003 & 50 & 32 & 14 & 31.8 \\
\hline \multicolumn{5}{|l|}{ A. niger } \\
\hline AN-001 & 11 & - & - & - \\
\hline $\mathrm{AN}-002$ & 11.8 & - & - & - \\
\hline AN-003 & 38 & 20 & 30 & 31 \\
\hline AN-004 & 40 & 21 & 35 & 38 \\
\hline AN-005 & 36 & 23 & 40 & 38 \\
\hline AN-006 & 12 & - & - & - \\
\hline AN-007 & 36 & 23 & 33 & - \\
\hline AN-008 & 13 & - & 10 & - \\
\hline AN-009 & 25 & - & - & - \\
\hline \multicolumn{5}{|l|}{ A. terreus } \\
\hline AT-001 & 33 & 11 & - & 21 \\
\hline AT-002 & 31 & 21 & 14 & 26.4 \\
\hline AT-003 & 33 & 10 & 10 & 15.8 \\
\hline AT-004 & 50 & 20 & - & - \\
\hline AT-005 & 45 & 18 & 15 & 20.3 \\
\hline A. flavus & 41 & - & 20 & - \\
\hline \multicolumn{5}{|c|}{$\begin{array}{l}\text { Aspergillus } \\
\text { species }\end{array}$} \\
\hline ASp-001 & 35 & 20 & 27 & 26.8 \\
\hline ASp-002 & 54.8 & 50.4 & 48.6 & 50 \\
\hline ASp-003 & 52.6 & 44.7 & 38.2 & 50 \\
\hline ASp-004 & 40 & - & - & - \\
\hline ASp-005 & 5 & - & - & - \\
\hline ASp-006 & 48.9 & 34.1 & 33.5 & 45.7 \\
\hline ASp-007 & 40 & 35 & 37 & 40 \\
\hline ASp-008 & 45 & 30 & 40 & 36.5 \\
\hline ASp-009 & 9 & - & - & - \\
\hline
\end{tabular}

\#AF is the susceptible strain obtained from NBAIM, Mau, India, * signifies isolates with no inhibiton zone for any of the azoles used in present study, (-) signifies no zone of inhibition observed. 


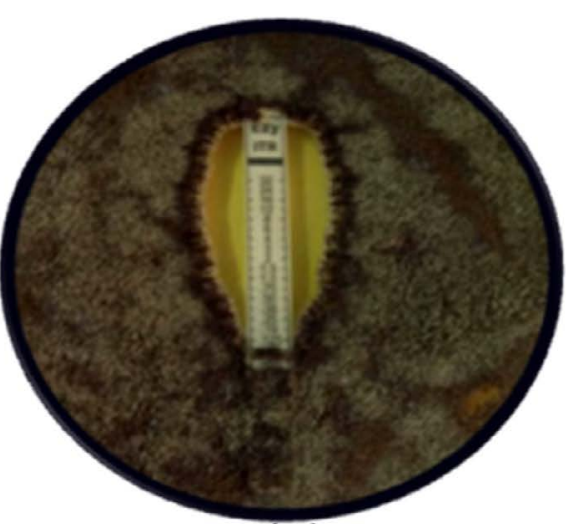

(a)

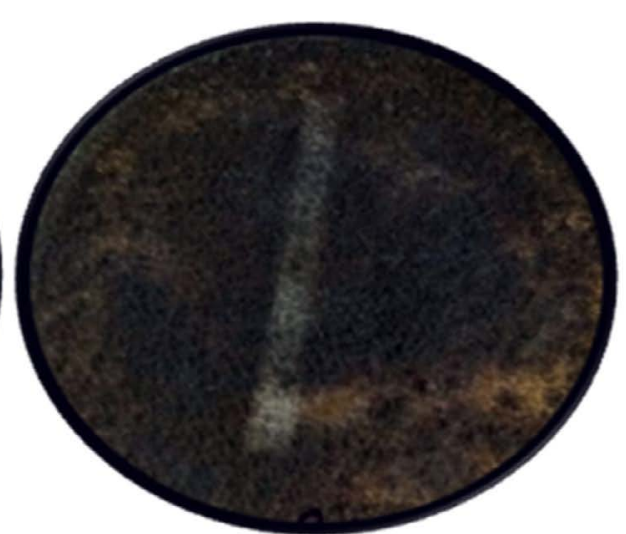

(b)

Fig. 2. E-strip result for susceptible and resistant strains. (a): Inhibition zone by itraconazole-strip against susceptible control strain, (b): no inhibition in resistant isolates.

\section{Antifungal susceptibility testing (AFST)}

At present, CLSI is one of the universally recognized standard methods to perform in vitro AFST for either yeasts or filamentous fungi (Sanguinetti and Posteraro, 2018) which apply broth micro-dilution method. The antifungal activity is expressed as MIC of antifungal drug indicating the minimal drug concentration that inhibits fungal growth. In the present study, resistant and susceptible isolates were distinguished using broth micro-dilution and were confirmed resistant on the basis of having MICs above ECVs and breakpoints. AF-003, AF-006, AF-008 had high $\mathrm{MIC}_{100}$ in comparison to ECV against azole antifungals, where no hyphal growth was observed in 96 well micro-plate. No $\mathrm{MIC}_{100}$ was observed for fluconazole in all the resistant isolates. Susceptible strain had $\mathrm{MIC}_{100}<\mathrm{ECV}$ against azole antifungals (Table 2).

Table 2. $\mathrm{MIC}_{100}$ of Aspergillus isolates

\begin{tabular}{|c|c|c|c|c|c|c|c|c|}
\hline \multirow[t]{2}{*}{ Isolates } & \multicolumn{2}{|c|}{ Itraconazole } & \multicolumn{2}{|c|}{ Voriconazole } & \multicolumn{2}{|c|}{ Ketoconazole } & \multicolumn{2}{|l|}{ Fluconazole } \\
\hline & $\begin{array}{c}\text { ECV } \\
(\mu \mathrm{g} / \mathrm{ml})\end{array}$ & $\begin{array}{l}\mathrm{MIC}_{100} \\
(\mu \mathrm{g} / \mathrm{ml})\end{array}$ & $\begin{array}{c}\text { ECV } \\
(\mu \mathrm{g} / \mathrm{ml})\end{array}$ & $\begin{array}{l}\mathrm{MIC}_{100} \\
(\mu \mathrm{g} / \mathrm{ml})\end{array}$ & $\begin{array}{c}\text { ECV } \\
(\mu \mathrm{g} / \mathrm{ml})\end{array}$ & $\begin{array}{l}\mathrm{MIC}_{100} \\
(\mu \mathrm{g} / \mathrm{ml})\end{array}$ & $\begin{array}{c}\text { ECV } \\
(\mu \mathrm{g} / \mathrm{ml})\end{array}$ & $\begin{array}{l}\mathrm{MIC}_{100} \\
(\mu \mathrm{g} / \mathrm{ml})\end{array}$ \\
\hline${ }^{\#} \mathrm{AF}$ & 1 & 0.39 & 1 & 0.78 & 1 & 0.78 & 64 & 50 \\
\hline AF-003 & 1 & 3.12 & 1 & - & 1 & 3.12 & 64 & - \\
\hline AF-006 & 1 & 3.12 & 1 & 3.12 & 1 & 3.12 & 64 & - \\
\hline AF-008 & 1 & 6.25 & 1 & 12.5 & 1 & 6.25 & 64 & - \\
\hline
\end{tabular}

$\mathrm{MIC}_{100}$ : Minimum Inhibitory Concentration, "AF is the susceptible strain obtained from NBAIM, Mau, India, (-) signifies no $\mathrm{MIC}_{100,}{ }^{100}$ ECV: Epidemiological cut-off values.

Hence, among 41 environmental Aspergillus isolates from various parts of North India, $7.3 \%(n=3)$ isolates were resistant to all the tested azole drugs, $19.5 \%(n=8)$ were diazole resistant and $17.07 \%(n=7)$ were resistant to itraconazole only. Multi-triazole resistance was only found in A. fumigatus which is similar to the results observed by Chowdhary et al., 2015. The correlation between azole-based fungicides and resistant strains has been long argued; however, in recent years resistant isolates have also been found in environmental samples in several countries (Snelders et al., 2009; Mortensen et al., 2010; Berger et al., 2017). Among all Aspergillus species, the azole resistance was observed maximally in $A$. fumigatus. 


\section{CONCLUSION}

Environmental azole resistance Aspergillus strains are present in environment of North India. This indicates the possible exposure of the population to these resistant strains. The regular screening of environmental azole resistant Aspergillus strains is crucial to analyze development of resistance in human pathogenic fungi and developing mitigation strategies.

\section{ACKNOWLEDGEMENTS}

The authors would like to thank Amity University Uttar Pradesh for providing the infrastructure and facility for research.

\section{CONFLICTS OF INTEREST}

The authors declare that there are no conflict of interest.

\section{REFERENCES}

1. Horsfall JG. Fungi and fungicides. The story of nonconformist. Annu Rev Phytopathol, 1975; 13: 1-14.

2. Hof H. Critical annotations to the use of azole antifungals for plant protection. Antimicrob Agents Chemother, 2001; 45(11):2987-2990.

3. Russel PE. A century of fungicide evolution. J Agric Sci, 2005; 143(1): 11-25.

4. e Ribas ADR, Spolti P, Ponte EMD, Donato KZ, Schrekker $H$, Fuentefria AM. Is the emergence of fungal resistance to medical triazoles related to their use in the agroecosystems? A mini review. Braz J Microbiol, 2016; 47(4): 793-799.

5. Snelders E, Huis In't Veld RA, Rijs AJ, Kema GH, MelchersWJ, Verweij PE. Possible environmental origin of resistance of Aspergillus fumigatus to medical triazoles. Appl Environ Microbiol, 2009; 75(12): 40534057.

6. Cools HJ, Fraaije BA. Update on mechanisms of azole resistance in Mycosphaerella graminicola and implications for future control. Pest Manage Sci, 2013; 69(2): 150-155.

7. Berger S, Chazli YE, Babu AF, Coste AT. Azole Resistance in Aspergillus fumigatus: A Consequence of Antifungal Use in Agriculture? Front Microbiol, 2017; 8: 1024.

8. Kumar MKP, Gowda DKS, Moudgal R, Kumar NK, Gowda KTP, Vishwanath K. 2013. Impact of Fungicides on Rice Production in India, pp. 77-98. In Mizuho Nita (ed), Fungicides - Showcases of Integrated Plant Disease Management from Around the World, chapter 4, InTech Open, Rijeka.

9. Meneau I, Sanglard D. Azole and fungicide resistance in clinical and environmental Aspergillus fumigatus isolates. Med Mycol, 2005; 43(S1): S307-311.

10. Bowyer P, Denning DW. Environmental fungicides and triazole resistance in Aspergillus. Pest Manage Sci, 2014; 70(2): 173-178.

11. Lelievre L, Groh M, Angebault C, Maherault AC, Didier
E, Bougnoux ME. Azole resistant Aspergillus fumigatus: an emerging problem. Med Mal Infect, 2013; 43(4): 139-145.

12. Snelders E, Camps SMT, Karawajczyk A, Schaftenaar $\mathrm{G}$, Kema GHJ, van der Lee HA, Klaassen $\mathrm{CH}$, Melchers WJG, erweij PE. Triazole fungicides can induce cross-resistance to medical triazoles in Aspergillus fumigatus. PLoS ONE, 2012; 7(3): e31801.

13. Palazzini JM, Torres AM, Chilze SN. Tolerance of triazole-based fungicides by biocontrol agents used to control Fusarium head blight in wheat in Argentina. Lett Appl Microbiol, 2018; 66(5): 434-438.

14. Chang H, Ashu E, Sharma C, Kathuria S, Chowdhary A, Xu J. Diversity and origins of Indian multi-triazole resistant strains of Aspergillus fumigatus. Mycoses, 2016; 59(7): 450-466

15. Perlin DS, Shor E, Zhao Y. Update on antifungal drug resistance. Curr Clin Microbiol Rep, 2015; 2(2): 84-95.

16. Verweij PE, Snelders E, Kema GH, Mellado E, Melchers WJ. Azole resistance in Aspergillus fumigatus: a sideeffect of environmental fungicide use? Lancet Infect Dis, 2009; 9(12):789-95.

17. Chowdhary A, Kathuria S, Randhawa HS, Gaur SN, Klaassen $\mathrm{CH}$, Meis JF. Isolation of multiple-triazoleresistant Aspergillus fumigatus strains carrying the $\mathrm{TR} / \mathrm{L98H}$ mutations in the cyp51A gene in India. $J$ Antimicrob Chem, 2012; 67(2): 362-366.

18. Brent KJ, Hollomon DW. Fungicide resistance in crop pathogens: How can it be managed? pp. 3-50. FRAC Monograph No $1,2^{\text {nd }}$ revised Ed. Fungicide Resistance Action Committee, Brussels, Belgium, 2007.

19. Pham CD, Reiss E, Hagen F, Meis JR, Lockhart SR. Passive surveillance for azole-resistant Asper-gillus fumigatus, United States, 2011-2013. Emerg Infect Dis, 2014; 20(9):1498-503.

20. Snelders E, van der Lee HA, Kuijpers J, Rijs AJMM, Varga J. Emergence of azole resistance in Aspergillus fumigatus and spread of a single resistance mechanism. PLOS Med, 2008; 5(11): 1629-1637.

21. Rodriguez-Tudela JL, Alcazar-Fuoli L, Mellado E, Alastruey-Izquierdo A, Monzon A, Cuenca-Estrella M. Epidemiological cutoffs and cross-resistance to azole drugs in Aspergillus fumigates. Antimicrob Agents Chemother, 2008; 52(7): 2468-2472.

22. Howard SJ, Pasqualotto AC, Denning DW. Azole resistance in allergic bronchopulmonary aspergillosis and Aspergillus bronchitis. Clin Microbiol Infect, 2010; 16(6): 683-688.

23. Mortensen KL, Mellado E, Lass-Flyrl C, RodriguezTudela JL, Johansen HK, Arendrup MC. Environ-mental study of azole-resistant Aspergillus fumigatus and other Aspergilli in Austria, Denmark, and Spain. Antimicrob Agents Chemother, 2010; 54(11): 45454549.

24. Lockhart SR, Frade JP, Etienne KA, Pfaller MA, Diekema DJ, Balajee SA. Azole resistance in Aspergillus fumigatus isolates from the ARTEMIS global surveillance study is primarily due to the TR/L98H mutation in the cyp51A gene. Antimicrob Agents Chemother, 2011; 55(9): 4465-4468.

25. Burgel PR, Baixench MT, Amsellem M, Audureau E, ChapronJ, Kanaan R, et al. High prevalence of azole- 
resistant Aspergillus fumigatus in adults with cystic fibrosis exposed to itraconazole. Antimicrob Agents Chemother, 2012; 56(2): 869-874.

26. Van der Linden JWM, Arendrup MC, Warris A, Lagrou $\mathrm{K}$, Pelloux $\mathrm{H}$, Hauser PM, et al. Prospective multicenter international surveillance of azole resistance in Aspergillus fumigatus. Emerg Infect Dis, 2015; 21(6): 1041-1044.

27. Howard SJ, Cerar D, Anderson MJ, Albarrag A, Fisher $M C$, Pasqualotto $A C$, et al. Frequency and evolution of azole resistance in Aspergillus fumigatus associated with treatment failure. Emerg. Infect. Dis, 2009; 15(7): 1068-1076.

28. Bueid A, Howard SJ, Moore CB, Richardson MD, Harrison E, Bowyer P, et al. Azole antifungal resistance in Aspergillus fumigatus: 2008 and 2009. Antimicrob Agents Chemother, 2010; 65(10):2116-2118.

29. van der Linden JWM, Snelders E, Kampinga GA, Rijnders BJA, Mattsson E, Debets-Ossenkopp YJ, et al. Clinical Implications of azole resistance in Aspergillus fumigatus, the Netherlands, 2007-2009. Emerg Infect Dis, 2011; 17(10): 1846-1854.

30. Burgel PR, Baixench MT, Amsellem M, Audureau E, Chapron J, Kanaan R, et al. High prevalence of azoleresistant Aspergillus fumigatus in adults with cystic fibrosis exposed to itraconazole. Antimicrob Agents Chemother, 2012; 56(2):869-874.

31. Badali H, Vaezi A, Haghani I, Yazdanparast SA, Hedayati MT, Mousavi B, et al. Environmental study of azoleresistant Aspergillus fumigatus with TR34/L98H mutations in the cyp51A gene in Iran. Mycoses, 2013; 56(6): 659-663.

32. Bader $\mathrm{O}$, Weig $\mathrm{M}$, Richard $\mathrm{U}$, Lugert $\mathrm{R}$, Kuhns $\mathrm{M}$, Christner M, et al. cyp51A-Based mechanisms of Aspergillus fumigatus azole drug resistance present in clinical samples from Germany. Antimicrob Agents Chemother, 2013; 57(8): 3513-3517.

33. van Ingen J, van der Lee HA, Rijs TAJ, Zoll J, Leenstra T, Melchers WJG, et al. Azole, polyene and echinocandin MIC distributions for wild-type, $\mathrm{TR}_{34} / \mathrm{L} 98 \mathrm{H}$ and $\mathrm{TR}_{46} /$ $\mathrm{Y} 121 \mathrm{~F} / \mathrm{T} 289 \mathrm{~A}$ Aspergillus fumigatus isolates in the Netherlands. I Antimicrob Chem, 2015; 70(1): 178-181.

34. Chowdhary A, Sharma C, Kathuria S, Hagen F, Meis JF. Prevalence and mechanism of triazole resistance in Aspergillus fumigatus in a referral chest hospital in Delhi, India and an update of the situation in Asia. Front Microbiol, 2015; 6:428.

35. de Hoog GS, Guarro J, Gene J, Figueras MJ. Atlas of clinical fungi, pp. 1126. 2nd ed. Centraalbureau voor Schimmelcultures (CBS), Utrecht, Netherlands, 2000.

36. Klich MA. Identification of common Aspergillus species. Centraalbureau voor Schimmelcultures (CBS), Utrecht, Netherlands, 2002, Pp 116.

37. McClenny. Laboratory detection and identification of Aspergillus species by microscopic observation and culture: the traditional approach. Med Mycol, 2005; 43(S1): 125-128.

38. Nugent LK, Sangvichen E, Sihanonth P, Ruchikachorn $\mathrm{N}$, Whalley AJ. A revised method for the observation of conidiogenous structures in fungi. Mycologist, 2006; 20(3): 111-114.
39. Nweze El, Mukherjee PK, Ghannoum MA. Agarbased disk diffusion assay for susceptibility testing of dermatophytes. J Clin Microbiol, 2010; 48(10): 37503752.

40. Pfaller JB, Messer SA, Hollis RJ, Diekma DJ, Pfaller MA. In vitro susceptibility testing of Asper-gillus spp.: Comparison of etest and reference microdilution methods for determining vorico-nazole and itraconazole MICs. J Clin Microbiol, 2003; 41(3): 11261129.

41. Clinical and laboratory Standards Institute. Reference method for broth dilution antifungal susceptibility testing of filamentous fungi: Approved Standard, $2^{\text {nd }}$ Ed. CLSI document M38- A2.Wayne, Pennsylvania, 2008.

42. Espinel-Ingroff $A$, Cuenca-Estrella $M$, Fothergill $A$, Fuller J, Ghannoum M, Johnsn E, et al. Wild-Type MIC Distributions and Epidemiological Cutoff Values for Amphotericin B and Aspergillus spp. for the CLSI Broth Microdilution Method (M38-A2 Document). Antimicrob Agents Chemother, 2011a; 55(11): 51505154.

43. Lass-Florl C. Susceptibility testing in Aspergillus species complex. Clin Microbiol Infect, 2014; 20(S6): 49-53

44. Alastruey-Izquierdo A, Melhem MS, Bonfietti LX, Rodriguez-Tudela JL. Susceptibility test for fungi: Clinical and laboratorial correlations in medical mycology. Rev Inst Med Trop Sao Paulo, 2015; 57(S19): 57-64.

45. Verweij PE, Chowdhary A, Melchers WJG, Meis JF. Azole resistance in Aspergillus fumigatus: Can we retain the clinical use of mold-active antifungal azoles? Clin Infec Dis, 2016; 62(3): 362-368.

46. Khalil AMA, Hashem AH. Morphological Changes of Conidiogenesis in Two Aspergillus Species. J Pure Appl Microbiol, 2018; 12(4), 2041-2048.

47. Chowdhary A, Sharma C, Kathuria S, Hagen F, Meis JF. Azole-resistant Aspergillus fumigatus with the environmental TR46/Y121F/T289A mutation in India. J Antimicrob Chemother, 2014; 69(2): 555-571.

48. Dudakova A, Spiess B, Tangwattanachuleeporn M, Sasse $C$, Buchheidt D, Weig $M$, et al. Molecular tools for the detection and deduction of azole antifungal drug resistance phenotypes in Aspergillus species. Clin. Microbiol. Rev, 2017; 30(4): 1065-1091.

49. Espinel-Ingroff A, Canton E, Fothergill A, Ghannoum M, Johnson E, Jones RN, et al. Quality Control Guidelines for Amphotericin B, Itraconazole, Posaconazole, and Voriconazole Disk Diffusion Susceptibility Tests with Nonsupplemented Mueller-Hinton Agar (CLSI M51-A Document) for Nondermatophyte Filamentous Fungi. J Clin Microbiol, 2011b; 49(7): 2568-2571.

50. Al-Wathiqi F, Ahmad S, Khan Z. Molecular identification and antifungal susceptibility profile of Aspergillus flavus isolates recovered from clinical specimens in Kuwait. BMC Infect Dis, 2013, 13:126.

51. Posteraro B, Sanguinetti M. The future of fungal susceptibility testing. Future Microbiol, 2014; 9(8): 947-967.

52. Sanguinetti M, Posteraro B. Susceptibility Testing of Fungi to Antifungal Drugs. J Fungi, 2018; 4(3): 110- 126. 